Available online at GSC Online Press Directory

GSC Biological and Pharmaceutical Sciences

e-ISSN: 2581-3250, CODEN (USA): GBPSC2

Journal homepage: https://www.gsconlinepress.com/journals/gscbps

(RESEARCH ARTICLE)

\title{
Study on physical properties of Indian based ayurvedic medicine: Abhrakh bhasma as nanomaterials by employing modern scientific tools
}

\author{
Singh Rakesh Kumar ${ }^{1,}{ }^{*}$, Kumar Sanjay ${ }^{1}$, Aman Abhay Kumar ${ }^{1}$, Kumar Sunil ${ }^{2}$ and Kar Manoranjan ${ }^{2}$ \\ ${ }^{1}$ Aryabhatta Centre for Nano Science and Nanotechnology, School of Engineering and Technology, Aryabhatta \\ Knowledge University, Patna, 800001, India. \\ ${ }^{2}$ Department of Physics, Indian Institute of Technology(IIT) Patna, Bihta, 801103, India.
}

Publication history: Received on 12 August 2018; revised on 08 September 2018; accepted on 10 October 2018

Article DOI: https://doi.org/10.30574/gscbps.2018.5.2.0100

\begin{abstract}
Abhrakh bhasma is an Ayurvedic medicine widely used for treating several diseases such as; pernicious, sickle cell anemia, Bell's palsy, hepatic dysfunction, leukemia, sex debility, cystic fibrosis, post encephalic dysfunction and cervical dysplasia etc. An Ayurveda bhasma is a medicine, which is used since ancient time and claimed to be very useful medicine at Nano metric scale. However there is a need of scientific evidence of such Ayurvedic products using modern scientific techniques of $21^{\text {st }}$ century. The physical behavior was measured by X-ray diffractometer (XRD), fourier transform spectroscopy (FTIR), vibrating sample magnetometer (VSM), scanning electron microscopy (SEM), and photoluminescence (PL) spectrometer. Abhrakh bhasma is prepared by using mica as a base materials. X-ray diffraction and SEM analysis revealed that this bhasma is in nanocrystalline form and, can be considered as nanomedicine. Magnetic hysteresis $(\mathrm{M} \sim \mathrm{H})$ loop study by using the VSM reveals the super paramagnetic nature. Luminescence in bhasma was observed in visible region upon excitation of $200 \mathrm{~nm}$ laser source. This investigation reveals that, the Abhrakh bhasma may not only used as nanomedicine but also can be employed a materials for various other technological applications due to both magnetic as well as luminescence properties. Preliminary testing of Abhrakh bhasma nanoparticles was examined on Staphylococcus aureus and Escherichia coli bacteria.
\end{abstract}

Keywords: Ayurveda; Abhrakh bhasma; Nanomedicine; XRD; SEM; Magnetic; Luminescence properties

\section{Introduction}

An Ayurveda bhasma is Indian traditional Ayurvedic medicine obtained naturally. It being used since ancient time in India and also some other parts of the world. This medicine is accepted well in India. However, these medicines were being used on practice by BAIDYA (Ayurvedic practioner) in ancient India. Recently there is a considerable interest lies on scientific community to understand the physical properties of these Ayurvedic bhasma. The recent study reveals that the size of those bhasma materials almost lies between 1-100 nm range, as confirmed by X-ray diffractometer and Scanning Electron Microscopy [1-2]. Ayurvedic Abhrakh bhasma is the mineral of mica $\left[\mathrm{K}(\mathrm{Mg}, \mathrm{Fe})_{3}\left(\mathrm{AlSiO}{ }_{10}\right)(\mathrm{OH})_{2}\right.$ and widely used for treating several diseases such as; pernicious, sickle cell anemia, Bell's palsy, hepatic dysfunction, leukemia, sex debility, cystic fibrosis, post encephalic dysfunction and cervical dysplasia etc. Its primary use is as aphrodisiac, astringent and restorative (powerful cell regenerator). It is also called for its penetrative and spreading property in the whole body and various micro tissues. It is an alternative, aphrodisiac, anti-pyretic, carminative, hematinic and proven rejuvenator [3-5]. According to some new findings, bhasma are claimed to be biologically produced nanoparticle using Ayurvedic methods [6-8]. The details of Ayurvedic methods for preparation of Abhrakh bhasma are explained in detail Ayurvedic text [9-10]. Modern scientific tools such as; X-ray diffractometer (TTRX-IIIRigaku, Japan), Fourier Transform Infrared spectroscopy (Frontier, PerkinElmer, UK), Vibrating sample magnetometer

\footnotetext{
${ }^{*}$ Corresponding author

E-mail address: rakeshsinghpu@gmail.com
}

Copyright (C) 2018 Author(s) retain the copyright of this article. This article is published under the terms of the Creative Commons Attribution Liscense 4.0. 
(7410, LakeShore, USA), Scanning Electron Microscopy (EVO 18 Research, Zeiss UK), and Photoluminescence (LS-55, PerkinElmer, Germany) Spectrometer have been employed to characterize the prepared Abhrakh bhasma. The structural, size, chemical constituents, magnetization, colour in the bhasma are reported. The preliminary testing of antimicrobial activity was examined on Staphylococcus aureus and Escherichia coli microorganism which is reported here. Hence, it is interesting to note that the present article may help to Ayurvedic doctors to implement Abhrakh bhasma in a better way for the treatment. Also the other applications of the bhasma can be explored.

\section{Material and methods}

Abhrakh bhasma has been prepared by using mica as a base materials. The pieces of mica are heated till they become red and it dipped in the decoction of cow urine and cooled it. This process is repeated for seven times after that mica powder cover with paddy and it was kept in a blanket and tied firmly. Then it is kept in sour gruel for a day and thereafter, it was rubbed with hand so that mica entirely gets out into the sour gruel. This is taken out and washed and dried in the sun light. After dried, it is ready for incineration. Equal amount of jaggery is mixed with dhanyabhrakh and was processed with the leaves juice of Eranda and made into small discs which were dried in the sun light and, heated in the sealed saucers. The leaves of vata (Ficus bengalensis) were placed above and beneath the discs before heating. This process is repeated for three times, a lusterless Abhrakh bhasma powder was get ready. The details of preparation of such bhasma also can be found in the Ayurvedic [9-10].

\section{Results and discussion}

\subsection{Structural and microstructural studies}

An X-ray Diffraction (PXRD) technique uses this principle to elucidate the crystalline nature of materials. The scattering of X-rays from atoms produce a diffraction pattern that contains information about the atomic arrangement in crystal. The sample kept on sample holder and take crystallography. The crystallographic phase analysis of prepared Abhrakh bhasma was carried out by employing the X-ray diffractometer, with CuK $\alpha$ radiation source $(\lambda=1.5418 \AA$ ) and, are shown in figure 1 (a) and (b) for clear visibility of the peaks. It is divided into two parts (a) $10^{\circ}$ to $35^{\circ}$ and (b) $35^{\circ}$ to $80^{\circ}$ of $2 \theta$ values. There are several diffraction peaks are observed, which could be identified by using the ICDD PDF no. 98-007-4571, 98-006-8756, 98-006-0684 and 98-008-0684 and these are correspond to different elements which are enlisted in table 1 . The maximum intensity peak in XRD pattern of Abhrakh bhasma shown in figure 1 (a-b) is indexed to $\mathrm{Mg}_{2} \mathrm{O}_{4} \mathrm{Si}_{1}$. Hence, it is assumed that the Abhrakh bhasma is mostly a byproduct of magnesium. Similar result has been reported by other research group [11]. The XRD analysis reveals that the Abhrakh bhasma contains various other elements such as iron, magnesium, potassium, calcium, aluminum, silica and sodium with oxygen.
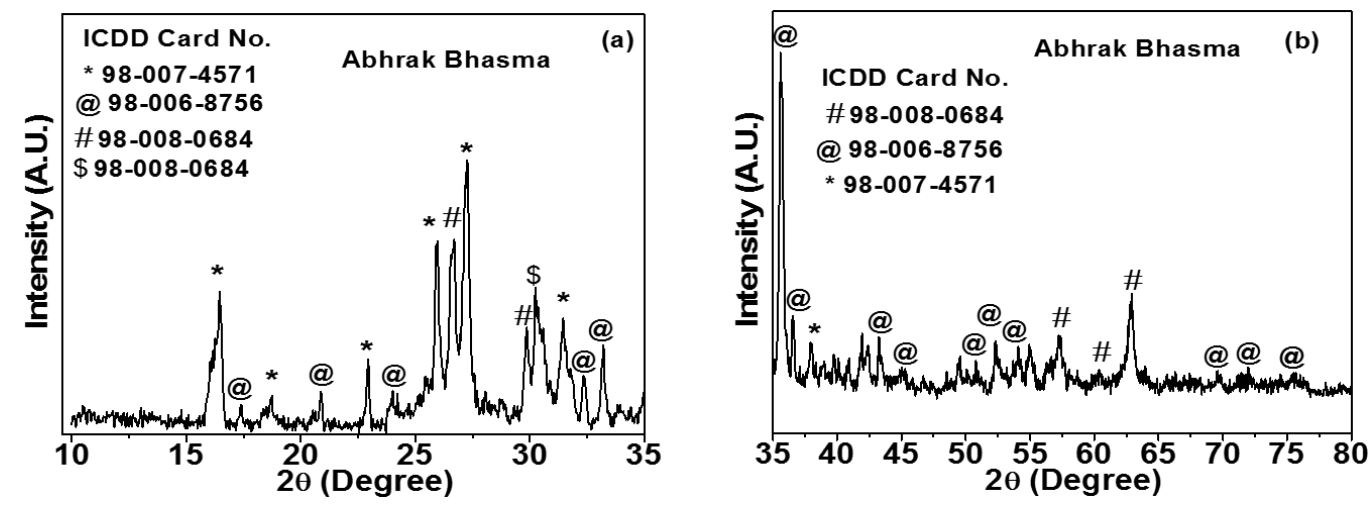

Figure 1. XRD patterns of Abhrakh bhasma (a) from 2 $\theta=10$ degree to 35 degree and (b) from 35 degree - 80 degree. XRD pattern has been separated for the better presentation and visibility only

The average crystallite size of the Abhrakh bhasma is calculated by employing the Sherrer's formula [12]

$$
\mathrm{d}=\mathrm{K} \lambda / \beta \cos \theta
$$

Where $\mathrm{K}$ is a constant which is equal to $0.9, \beta$ is the full width half minimum (FWHM), $\theta$ is the Braggs' angle and $\lambda$ is the wavelength of $\mathrm{Cu}-\mathrm{K} \alpha$ radiation. 
The crystallite size calculation was carried out with considering all intense diffraction peaks. The above equation yields the average crystalline size $\sim 24 \pm 4 \mathrm{~nm}$. Thus the XRD study concludes the Abharakh bhasma is in nanocrystalline form.

Table 1. The ICDD database card numbers with chemical formula for Abhrakh bhasma

\begin{tabular}{llll}
\hline $\begin{array}{l}\text { Sr. } \\
\text { No. }\end{array}$ & $\begin{array}{l}\text { ICDD card } \\
\text { number }\end{array}$ & Compound name & Chemical formula \\
\hline 1 & $98-007-4571$ & $\begin{array}{l}\text { DipotassiumTecto- } \\
\text { magnesiopentasilicate }\end{array}$ & $\mathrm{K}_{2} \mathrm{Mg}_{1} \mathrm{O}_{12} \mathrm{Si}_{5}$ \\
2 & $98-006-8756$ & Forsterite & $\mathrm{Mg}_{2} \mathrm{O}_{4} \mathrm{Si}_{1}$ \\
3 & $98-008-0684$ & Diopside, aluminian & $\mathrm{Al}_{0.17} \mathrm{Ca}_{0.812} \mathrm{Fe}_{0.075} \mathrm{Mg}_{0.939} \mathrm{Na}_{0.174} \mathrm{O}_{6} \mathrm{Si}_{1.83}$ \\
4 & $98-008-5178$ & Magnesioferrite, aluminian & $\mathrm{Al}_{0.74} \mathrm{Fe}_{1.26} \mathrm{Mg}_{1} \mathrm{O}_{4}$ \\
\hline
\end{tabular}

\subsection{FTIR analysis}

FTIR measurement of Abrakh bhasma was observed by the KBr palate methods. In this method, obtained sample proper grind and mixed with potassium bromide $(\mathrm{KBr})$ at approximately 1:20 mass ratio with the help of mortar and pestle. The mixture is then pressed to make the thin pallets by palatalizer and applied pressure up to 6.5 tons. Spectra were observed with Frontier, Perkin-Elmer Singapore at room temperature. The FTIR spectrum of nanocrystalline Abhrakh bhasma is shown in figure 2. The absorption bands in transmission mode are in the range of 400 to $1700 \mathrm{~cm}^{-}$ 1 at room temperature. The functional groups available in Abhrakh bhasma with its corresponding wave number are enlisted in table 2. The functional groups identified in the FTIR spectra are well supported to the XRD analysis. The above two techniques reveals that the prepared Abhrakh bhasma is made of organic molecules from the herb which play a major role in different deceases as discussed in the previously reported work and also it is reported by several research groups [13-17]. The present investigation may help to Ayurvedic doctors and practitioners to treat the several diseases with the action of Abhrakh bhasma in safe way.

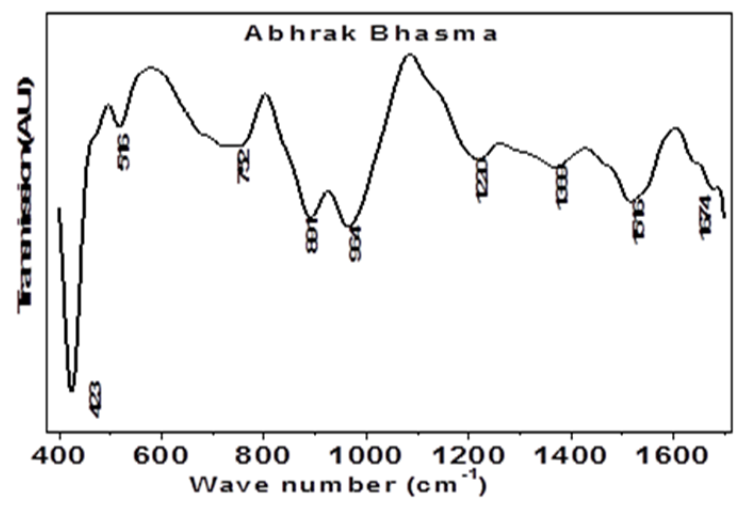

Figure 2. FTIR spectrum of Abhrakh bhasma

Table 2. FTIR Data for Abhrakh bhasma [13-17]

\begin{tabular}{lll}
\hline $\begin{array}{l}\text { Sr. } \\
\text { No. }\end{array}$ & Wavenumber $\left(\mathbf{c m}^{-\mathbf{1}} \mathbf{)}\right.$ & Functional group \\
\hline 1 & 423 & $\mathrm{Si}-\mathrm{O}-\mathrm{Si}$ \\
2 & 516 & $\mathrm{Fe}_{2} \mathrm{O}_{3}$ \\
3 & 752 & $\mathrm{C}-\mathrm{O}$ \\
4 & 891 & $\mathrm{Mg}-\mathrm{O}$ \\
5 & 964 & Stretching Si-O \\
6 & 1220 & $\mathrm{C}-\mathrm{O}-\mathrm{C}$ \\
7 & 1369 & $\mathrm{C}-\mathrm{H}$ \\
8 & 1516 & $\mathrm{Ca}-\mathrm{O}$ \\
9 & 1674 & $\mathrm{C}-\mathrm{O}$ \\
\hline
\end{tabular}




\subsection{SEM Measurement}

The scanning electron microscope images were taken at $14 \mathrm{KV}$ EHT with mm working distance and $35.57 \mathrm{kx} \& 70.96 \mathrm{kx}$ magnification. The powders were coated with Gold and Palladium mixture in spin coater and then the images were taken. The SEM micrograph of Abhrakh bhasma is shown the figure 3 (a) and (b) with different magnifications. It is observed that the average particle sizes are below $200 \mathrm{~nm}$. But earlier in XRD analysis, crystalline size was found to be $24 \mathrm{~nm}$. Both the experimental techniques analysis indicates that agglomeration of nanocrystallites in the samples. However, it is observed that the microstructure is uniform which must in contest is as concern for the disease treatment i.e. the action of medicine should be uniform for better action. The present study reveals that the present method of bhasma preparation can be used as a standard method to produce uniform particle size of Abhrakh bhasma for better use in disease treatment.

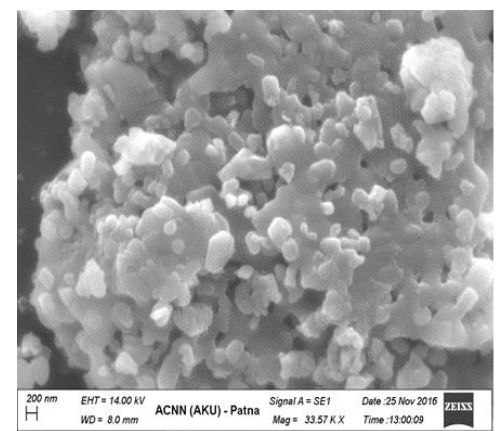

(a)

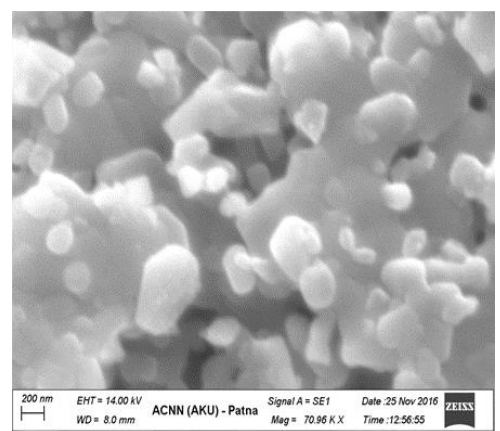

(b)

Figure 3. (a) and (b) SEM micrographs of Abhrakh bhasma in different magnifications

\subsection{Magnetic measurement}

Vibrating sample magnetometer is a powerful technique to study the magnetic properties of materials easily, reliably and accurately, as the movement of the sample allows discrimination of the background signals. We have used Teflon tape raped sample measurement at an applied external field up to $20 \mathrm{kOe}$. The magnetic hysteresis loop (M H loop) for Abhrakh bhasma is shown in the figure 4 (a) and (b). It reveals that the Abhrakh bhasma is magnetic in nature. However the coercivity is very low. It could be due to nanocrystalline nature of the Abhrakh bhasma, which is also observed from XRD analysis. The maximum saturation magnetization is found to be $\sim 1.3 \mathrm{emu} / \mathrm{g}$, which is comparable to very good magnetic materials. The ' $\mathrm{S}$ ' shape curve of M-H hysteresis loop reveals the super paramagnetic nature of the bhasma. However it needs further magnetic investigations for confirmation such as field cooled or zero field cooled magnetization measurement, ac- susceptibility etc. which is our future research problem which are beyond the scope of the present study. The coercivity is found to be around $1400 \mathrm{Oe}$, which is very good for using this as a natural magnet for magnetic memory device applications. So, the present study reveals that the present bhasma not only can be used for diseases treatment but also can be explored the green technological and engineering applications as, it has been prepared from the natural products.

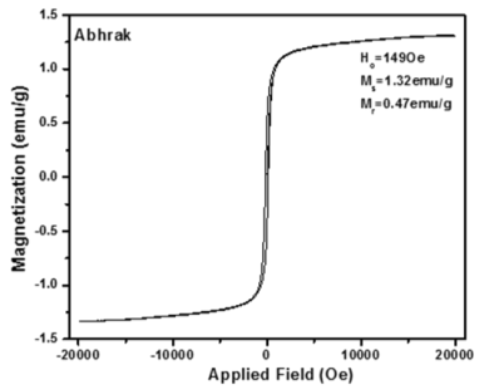

A

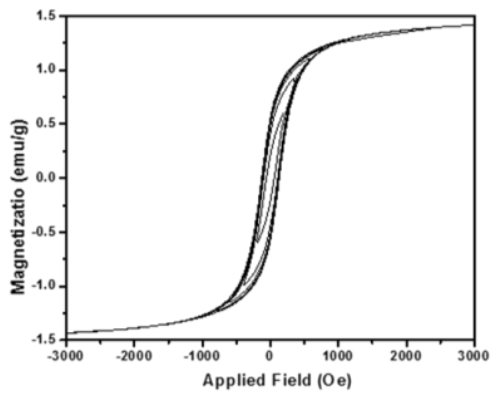

B

Figure 4. The $\mathrm{M} \sim \mathrm{H}$ hysteresis curve of Abhrakh bhasma as nanomaterials

Similar study on magnetic measurement has been reported by the other research groups and their magnetic parameters values are suitable for electronics materials, high frequency applications, memory devices etc. [18-20]. More important 
is that, the present study opens a window to motivate this natural bhasma for high contrast MRI (Magnetic resonance imaging) techniques. It needs further investigations. Hence, the present study opens a new window for natural Ayurvedic medicines.

\subsection{Luminescence study}

The powder samples kept on sample holder and measure the emission spectra. Figure 5 shows the room temperature PL spectrum and it is interesting to note that there are 5 peaks with different intensities which are in visible spectrum. The peaks are also in UV and NIR as shown in the figure also. Each element has optical spectrum. XRD analysis confirms the presence of $\mathrm{Fe}, \mathrm{K}, \mathrm{Al}$ etc. So, emission peaks may correspond to these elements or their oxides. Luminescence due to metal oxide compounds are also reported by other research groups [21-22]. Each bhasma have some color and such luminescence may be due to presence of different elements present in the compounds.

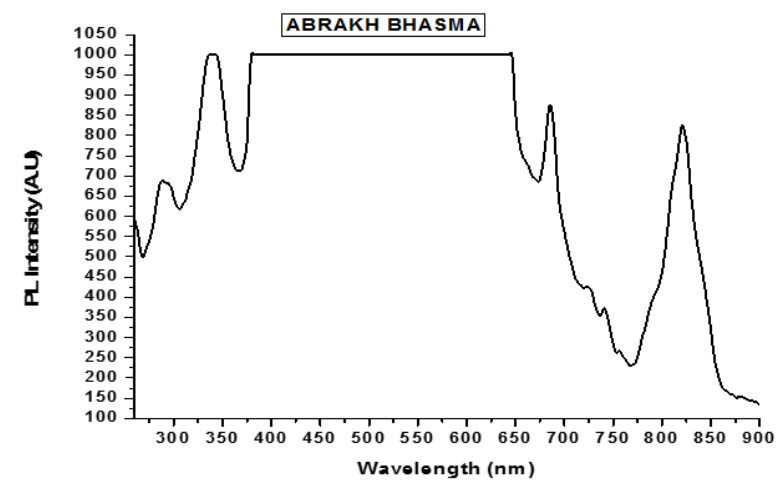

Figure 5. Photo Luminescence spectra of Abhrakh bhasma

\subsection{Antimicrobial study}

The preliminary testing of the Abrakh bhasma nanoparticles was examined on Staphylococcus aureus bacteria and $E$. coli. The determination of antimicrobial property of Abrakh Bhasma was observed by Kirby-Bauer disc diffusion method. In this method, a standard suspension of bacteria to be tested is inoculated on the surface of Mueller Hinton Agar (MHA) plates. We have use $40 \mu \mathrm{L}$ of Abrakh bhasma acetonic solution having concentration of $25 \mathrm{mg} / \mathrm{ml}$ was used. Effect of Abhrakh bhasma on E. coli and S. aureus microorganism an antimicrobial studies are shown in figure 6 (a) and 6(b). Acetone and without acetone treated Abhrakh bhasma (sample dilution $0.5 \mathrm{gm} / \mathrm{ml}$ ) and, amoxyclav have no any zone of inhibition shown after 18 hours incubation at $37^{\circ} \mathrm{C}$. So, Abhrakh bhasma and amoxyclav have not shown any antimicrobial properties for this particular bacteria strain. These results confirm that Abhrakh bhasma cannot be used for bacterial infection disease. However other bhasma shows antimicrobial effect such as Tamra bhasma which is reported earlier [23-25]

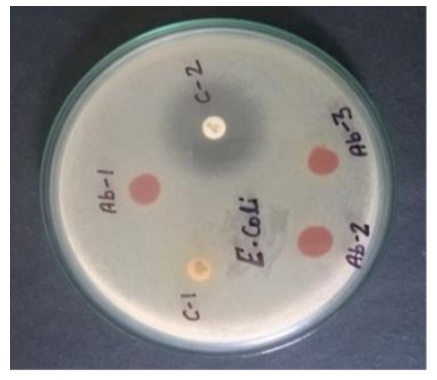

(A)

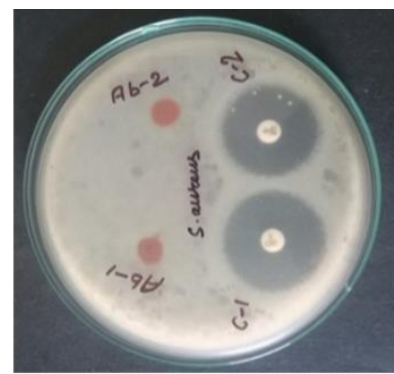

(B)

Figure 6. Antibacterial activity of Abhrakh bhasma on (A) - E. coli (B) - S. aureus

\section{Conclusions}

Abhrakh bhasma Indian based An Ayurvedic medicine can be prepared by the natural method. X ray diffraction and Scanning Electron microscopy results confirm the nanocrystalline size of the prepared Abhrakh bhasma. The XRD and FTIR techniques reveal that the prepared Abhrakh bhasma is made of organic molecules from the herbs which play a 
major role in different deceases. SEM results observed that the microstructure is uniform which must in contest is as concern for the disease treatment i.e. the action of medicine should be uniform for better treatment. The present study reveals that the method used in the present article can be used as a standard method to produce uniform particle size of Abhrakh bhasma. Magnetic hysteresis measurement shows that the coercivity is very low and the maximum saturation magnetization is found to be about $1.3 \mathrm{emu} / \mathrm{g}$, which is comparable with the good magnetic materials. The ' $\mathrm{S}$ ' shape curve of M-H hysteresis loop reveals the super paramagnetic nature of the Abhrakh bhasma. The coercivity is found to be around $1400 \mathrm{Oe}$, which is very good for using this natural product for magnetic memory devices applications. Therefore, the present study reveals that the Abhrakh bhasma not only can be used for diseases treatment but also, it can be explored for the technological and engineering applications without natural hazards. More important is that, the present study opens a window to motivate use of this natural bhasma for high contrast MRI (Magnetic resonance imaging) techniques. Hence, the present study opens a new window in natural Ayurvedic medicines.

\section{Compliance with ethical standards}

\section{Acknowledgments}

Thankful to Dr. Manoranjan Kar, Mr. Sunil Kumar of Indian Institute of Technology(IIT) Patna, for FTIR measurement and fruitful discussion. Also thankful to Dr. Jitendra Kumar, Science College Patna, Patna university for microbiology measurement. Moreover, authors are thankful to Aryabhatta Knowledge University Patna for financing the research expenses and Department of Education, Govt. of Bihar, which have been very supportive in establishment and functioning of Aryabhatta Center for Nanoscience and Nanotechnology, Aryabhatta Knowledge University, Patna.

\section{Disclosure of conflict of interest}

The authors declare that they have no conflict of interests. Dr. Sanjay Kumar, Dr. Abhay Kumar Aman and Dr. Rakesh Kumar Singh prepared bhasma materials and performed all measurement. Dr. Manoranjan Kar and Sunil Kumar helped in FTIR data measurements and interpretation of all measurements. The manuscript was edited and prepared by Dr. Rakesh Kumar Singh.

\section{References}

[1] Wedkar MP, Rode CV, Bendale YN, Patil KR and Prabhune AA. (2005). Preparation and Characterization of a copper based Indian traditional drug: Tamra bhasma. Journal of Pharmaceutical and Biomedical Analysis, 39,951-955.

[2] Singh RK, Kumar S, Aman AK, Kala S, Pradhan U, Kumar S and Kar M. (2016). Crystal Structure and Magnetic Property Studies on Nanocrystalline Lauh (Iron) Bhasma-An Ayurvedic Medicine. International Journal Of Ayurveda Alternative Medicine.4(1), 17-23

[3] Raisuddin S. (2004). Ayurvedic bhasma. In: Mishra LC (Eds), scientific basis for Ayurvedic Therapies. CRC Press LLC, New York, 83-100.

[4] Pal D, Sahu CK and Haldar A. (2014). Bhasma. The ancient Indian nanomedicine, Journal of Advanced Pharmaceutical, Technology and Research, 5(1), 4-12.

[5] Pal SK. (2015). The Ayurvedic bhasma: The ancient science of nanomedicine. Recent patents on Nanomedicine, 5,12-18

[6] Bhatia B and Kale PG. (2013). Analytical evolution of an Ayurvedic formulation-Abhrakh Bhasma. International Journal of Pharmaceutical Sciences Review and Research. 23, 17-23.

[7] Das S, Das MCD and Paul R. (2012). Swarn Bhasma in Cancer: A prospective clinical study, AYS, 33, 365-370.

[8] Kumar S, Singh RK, Aman AK, Kumar J, Kar M. (2017). Evaluation of iron oxide nanoparticles (NPs) on aging and age related metabolism and physiological changes in C.elegans. International Journal of Pharmaceutical sciences and Research, 8, 1000-04.

[9] Kumar S. (2018). Synthesis, characterization and applications of some ayurvedic bhasma as nanomedicine. Ph.D. thesis, Aryabhatta Knowledge University, Patna, India, 28-32.

[10] Sharma S. (1977). Rasa Ratna Samuchhaya. Second edition, Motilal Bnarsidas, New Delhi, India, 72-108. 
[11] Rai P, Gupta VM, Pathak R, Gupt LN, Kumar N and Singh RS (2010). Importance of media in the pharmaceutical processing's of metals and minerals - scanning electron microscopy study and energy dispersive x-ray analysis of abhraka (biotite). International Journal of Pharmacy and Pharmaceutical Sciences. 2(4), 121-123.

[12] Cullity B.D, (1978) Element of X-Ray diffraction, Addison-Wesley publishing company, Inc, Philippines. 101-102.

[13] Hareshwar S, Mayuri D and Raman B. (2017) Preparation of Abhrak bhasma and its evaluation on modern parameters. International Journal of Ayurveda and Pharma Research. 5(2), 30-36.

[14] Sharma S. (1977). Rasa Ratna Samuchhaya. Published by Motilal Banrasidas, New Delhi, 72-108.

[15] Gopinath H, and Shivashankar M. (2016). Herbo-metallic Indian nano-medicine Abhrak bhasma (MICA): A Periodical review. Research Journal of Pharmaceutical, Biological and Chemical Sciences, 7(6), 73-81.

[16] Subedi RP, Vartak RR and Kale PG. (2017). Study of General Properties of Abhrak Bhasma: A Nanomedicine International Journal of Pharmaceutical Sciences Review and Research 44(2),238-242

[17] Pathak R and Kumar N. (2015). Preparation and Characterization of Iron based Indian traditional drug -Abhrak Bhasma International Journal of Pharmaceutical \& Biological Archives . 6(1), 59 - 61.

[18] Verma RK., Singh RK, Narayan A, Verma L, Singh AK, Kumar A, Pathak PK and Aman AK. (2017). Low temperature synthesis of hexagonal Barium hexaferrite nanoparticles by annealing at $450^{\circ} \mathrm{C}$ followed by quenching. Journal of Thermal Analysis and Calorimetry, 129(2), 691-699.

[19] Kumar V, Singh RK, Shah J, Kotnala RK. (2012). Low dielectric loss of Mg doped Ni-Cu-Zn nano-ferrites Nanoparticles for power applications. Applied Surface Science, 258, 5342-5347.

[20] Singh RK, Upaadhyay C, Lyeak S and Yadav A. (2010). Cations distributions in $\mathrm{Ni}_{0.5} \mathrm{Zn}_{0.5} \mathrm{Fe}_{2} \mathrm{O}_{4}$ nanomaterials. Int. J. Sci. Eng. and Tech. (I-JEST), Special issue Nano iron oxides and composites - recent advances in Scientific and technological aspects, 2, 104-109.

[21] Peng WQ, Cong GW, Qu SC and Wang ZG. (2006). Synthesis and photoluminescence of ZnS:Cu nanoparticles. Optical Materials. 29,313-317.

[22] Reshma, Sandupatla R, and Veerasomaiah P. Synthesis. (2016). Characterization and photoluminescence study of $\mathrm{CuO}$ nanoparticles using aqueous solution method. Int J of Nanomaterials and Biostructures, 6(1), 30-33.

[23] Kumar TP, GS VK, and Singh S. (2010). In vitro antibacterial activity of Tamra Bhasma. International Journal of Ayurvedic Medicine, 1(1), 23-30.

[24] Tambekar DH and Dahikar SB. (2010). Screening antibacterial activity of some bhasma (Metal-Based herbal medicine) against enteric pathogens. Recent Research in Science and Technology, 2, 59-62.

\section{How to cite this article}

Singh RK, Kumar S, Aman AK, Kumar S and Kar M. (2018). Study on physical properties of Indian based ayurvedic medicine: Abhrakh bhasma as nanomaterials by employing modern scientific tools. GSC Biological and Pharmaceutical Sciences, 5(2), 41-47. 